\title{
Quem Sente é a Gente, mas é Preciso Relevar : a lombalgia na vida das trabalhadoras do setor têxtil de Blumenau - Santa Catarina
}

\author{
One Feels it but One Must Overlook it: low back pain in the \\ life of women working in the textile sector of Blumenau -
}

\author{
Karine Muniz Polizelli \\ Fisioterapeuta, Mestre em Saúde e Gestão do Trabalho, Profes- \\ sora do Curso de Fisioterapia da Faculdade Metropolitana de \\ Blumenau. \\ Endereço: Rua Clara Persuhn, 215, ap. 50I, Itoupava Seca, CEP \\ 89030140, Blumenau, SC, Brasil. \\ E-mail: karinem9ळhotmail.com

\section{Silvana Nair Leite} \\ Doutora em Saúde Pública. Professora da Universidade do Vale do \\ Itajaí. Programa de Mestrado em Saúde e Gestão do trabalho. \\ Endereço: Rua Uruguai, 458, Bloco 27, 3 andar, Centro, CEP 88302- \\ 202, Caixa-Postal 360, Itajaí, SC, Brasil. \\ E-mail: silvana.nairळhotmail.com
}

\section{Resumo}

Este estudo foi desenvolvido com o objetivo de compreender o enfrentamento da lombalgia no cotidiano de mulheres trabalhadoras do setor têxtil de Blumenau, Santa Catarina. Três mulheres trabalhadoras do setor têxtil daquela cidade foram as informantes principais do estudo, desenvolvido em encontros quinzenais e visitas a locais de trabalho. Foram utilizados como ferramentas de estudo um calendário com data e dias da semana para a marcação de dores relativas à lombalgia e uma Escala Análogo Visual (EAV). Além de relatos anotados em formulários de acompanhamento dos encontros quinzenais, utilizou-se um diário de campo para transcrição de fatos e relatos. Os dados coletados levaram à construção de duas categorias interpretativas: a dor lombar sob o aspecto da normalidade e a dor sentida. Os resultados da pesquisa levam à conclusão de que a lombalgia, sob o ponto de vista das trabalhadoras do setor têxtil de Blumenau, apresenta-se como uma espécie de conflito entre a dor normal, sem importância social, e a dor sentida e limitante, que traz sofrimentos e angústias no âmbito privado. A dualidade da lombalgia é marcante, pois são mulheres que têm dor, real para elas, com um impacto importante para suas vidas, mas elas mesmas esforçam-se por negligenciá-la, seguindo a concepção socialmente aceita para esta questão no contexto cultural da região. 0 conceito de lombalgia construído é de algo inerente à vida e ao trabalho, o que não permite o direito de estar doente.

Palavras-chave: Lombalgia; Mulheres; Trabalhadoras; Setor têxtil. 


\section{Abstract}

This study was developed with the objective of understanding how women working in the textile sector of Blumenau, state of Santa Catarina, cope with low back pain. Three women who worked in the textile sector of that city were the main informants of the study, developed in biweekly meetings and visits to workplaces. The study tools were a calendar with dates and week days, where the participants should mark the occurrence of low back pain, and a Visual Analog Scale (VAS). Besides accounts registered in forms during the meetings, a field diary for transcription of facts and accounts was used. The collected data led to the construction of two interpretative categories: low back pain under the aspect of normality and felt pain. In light of the results, it is possible to conclude that low back pain, in the point of view of the women from the textile sector of Blumenau, is expressed as a kind of conflict between normal pain, without social importance, and the felt pain, which is restrictive and brings suffering and anguish in the private scope. The duality of low back pain is outstanding, because these are women who feel pain, which is real for them and has an important impact on their lives, but they make an effort to neglect it, following the socially accepted conception for this issue in the region's cultural context. The constructed concept of low back pain is of something inherent in life and work, which does not give them the right to feel ill.

Keywords: Low Back Pain; Women; Workers; Textile Sector.

\section{Introdução}

Estudos antropológicos apontam os limites e a insuficiência da tecnologia biomédica quando se trata de mudar de forma perene o estado de saúde de uma população. Saúde e doença referem-se, de fato, a fenômenos complexos que conjugam fatores biológicos, sociológicos, econômicos, ambientais e culturais. São estados associados ao modo de vida e ao universo social e cultural da comunidade (Uchoa e Vidal, 1994).

Para que se possa construir uma explicação mínima para o fenômeno da doença, os indivíduos não necessitam de um conhecimento médico. Ao contrário, precisam das imagens fornecidas pelo seu meio sociocultural, o que significa dizer que para que as pessoas possam entender suas doenças, não lhes basta somente conhecer os agentes causadores, através das mais modernas técnicas de diagnóstico. Em algumas situações, o aspecto formal da doença é o que menos importa para as pessoas quando elaboram suas próprias interpretações sobre saúde, doença e tratamento, tendo como referência o quadro das suas vivências pessoais e culturais (Caroso e col., 2004).

Um dos dados mais importantes nos estudos socioantropológicos da saúde diz respeito ao conceito de experiência da enfermidade, que se refere basicamente à forma pela qual o indivíduo situa-se ou assume a situação de doença, conferindo-lhe significados e desenvolvendo modos rotineiros de lidar com a situação. É importante ter em conta que as respostas aos problemas criados pela doença constituem-se socialmente e remetem diretamente a um mundo compartilhado de práticas, crenças e valores. Na lida com a enfermidade, o doente e aqueles que estão envolvidos na situação (como familiares, amigos, vizinhos, terapeutas), formulam, (re) produzem e transmitem um conjunto de soluções, receitas práticas e proposições genéricas de acordo com o universo sociocultural do qual fazem parte (Alves e Rabelo, 1999).

Leite e Vasconcelos (2006) afirmam que a maneira como os indivíduos de uma determinada sociedade se posicionam em relação à doença, como a percebem, é tema de grande importância para o estudo social das doenças e das maneiras de lidar 
com elas. Desde a antiguidade a humanidade teve que encarar a doença como parte de seu cotidiano, desenvolvendo para isto estratégias diversas. 0 dia a dia é um lugar privilegiado para o estudo da sociedade e suas transformações.

Baseando-se nestes princípios e ao observar que um elevado número de pessoas que recorrem ao serviço de fisioterapia tem como diagnóstico clínico a lombalgia, e que, em sua maioria, as pessoas apresentam quadros crônicos de dor já instalados e vêm sofrendo com esta sintomalogia há anos, foi formulada a pergunta: Se as pessoas demoram tanto tempo para procurar ajuda profissional, como elas enfrentam em seu dia a dia a dor lombar?

No caso da lombalgia, a dor é uma experiência multidimensional. Possui componentes sensoriais, cognitivos, emocionais e comportamentais. A magnitude relativa de cada componente ajuda a determinar como o problema do indivíduo vai ser enfrentado. (Simmonds, 2002).

Diversos estudos sobre itinerários terapêuticos já demonstram conhecimentos e crenças que o indivíduo e a sociedade a que pertence têm uma opinião a respeito de sua dor e esta por sua vez irá influenciar o que farão com ela. Alguns indivíduos consideram a dor uma inconveniência, e tentam ignorá-la, enquanto outros se preocupam com ela e com seu significado procurando algum tipo de assistência, que pode ser desde a assistência profissional até as redes sociais ou informais, incluindo a família, amigos ou vizinhos. (Ferreira, 1994; Simmonds, 2002).

O grupo social ao qual se refere esta pesquisa são mulheres trabalhadoras do setor têxtil de Blumenau. Nesta cidade, em 2005, a lombalgia foi o diagnóstico responsável pelo maior número de encaminhamentos ao Centro de Referência em Saúde do Trabalhador da cidade de Blumenau (Cerest), correspondendo a $14,48 \%$ dos casos. Neste mesmo ano, o número de doenças ocupacionais investigadas e confirmadas destaca o sistema osteomuscular e o tecido conjuntivo como principais atingidos (Silva, 2007).

O objetivo inicial era saber mais sobre as concepções e causas da lombalgia, identificar os recursos terapêuticos mobilizados e analisar a influência da dor no cotidiano destas mulheres, afinal, entendiase que as pessoas, de alguma forma, enfrentavam a dor lombar em seu dia a dia. No entanto, ao iniciar a coleta de dados percebeu-se que muito havia a ser apreendido e que para compreender o ponto de vista das participantes seria preciso mais do que eleger objetivos específicos fragmentados sob o ponto de vista da racionalidade biomédica - sinais e sintomas, diagnóstico e tratamento decorrente.

Se a doença prevalece é necessário entender o que Alves e Rabelo (1999) descrevem: a enfermidade não é apenas uma "entidade biológica", que deva ser tratada como coisa; é também experiência que se constitui e adquire sentido no curso de interações entre indivíduos, grupos e instituições. A dor, ou a enfermidade, dota-se subjetivamente de sentido à proporção que se afirma como real para os membros da sociedade, que, por sua vez, a aceitam como real, justamente porque se origina no senso comum.

Este era um grande desafio de interpretação, pois era preciso abandonar a ideia biológica da lombalgia, em que as causas podem estar centradas em problemas de ordem postural, em decorrência de atividades diárias, mudanças de estrutura corporal (gravidez ou obesidade), permanência por tempo prolongado em posição incorreta, sentada ou em pé, comportamentos sedentários, doenças inflamatórias, degenerativas, defeitos congênitos e debilidade muscular (Knoplich, 2003), para entender a sensação de dor, os comportamentos que a envolvem, até as atitudes. Para isto, foi preciso compreender as expectativas do sujeito, suas experiências, sua condição de vida, sua cultura, e suas relações de poder na sociedade (Helman, 2006). Foi necessária uma mudança de postura da pesquisadora - fisioterapeuta que atua em atendimento clínico.

Foram meses de pesquisa, entre encontros e observações, onde se procurou uma aproximação com o contexto no qual as informantes tentavam entender qual a compreensão que faziam da dor lombar, voltando o olhar para as suas vivências, concepções e cultura.

\section{Metodologia}

A metodologia escolhida foi a de um estudo qualitativo utilizando o referencial da etnografia. A abordagem etnográfica se constrói tomando como base a ideia de que os comportamentos humanos só podem ser devidamente compreendidos e explicados 
se tomarmos como referência o contexto social onde eles atuam. Para tanto, torna-se fundamental entender o ponto de vista dos sujeitos sociais, procurando o significado de suas práticas (Victoria e col., 200o). Neste contexto, informantes e pesquisadores são parte ativa da pesquisa.

É importante esclarecer que a etnografia propriamente dita é pautada pela convivência mais intensa com os sujeitos ou grupo em estudo, muitas vezes com coabitação, portanto, nesta pesquisa foram utilizadas ferramentas e preceitos da etnografia para desenvolver o caminho metodológico.

\section{Aproximação do Campo}

Blumenau é uma cidade que se destacou como polo têxtil a partir de 1970, e que passou por um processo de reestruturação industrial no período de 1980, com a ascensão neoliberal, e em 1990, com as medidas econômicas do governo Collor, entre elas a abertura das importações, provocando a quebra de muitas empresas. Este processo de reestruturação industrial provocou a terceirização da produção e a precarização das relações de trabalho. Com isso, aumentou o desemprego e o grau de informalidade da economia, fazendo com que os trabalhadores ficassem à mercê desta conjuntura, sujeitando-se a qualquer tipo de organização nos processos produtivos. Este contexto ocasionou o surgimento das chamadas facções - pequenas estruturas fabris, muitas delas informais e instaladas em casa -, que fazem prestação de serviços para a indústria têxtil. Nestas facções predominam as intensas jornadas de trabalho e a remuneração, sendo diretamente proporcional à produção, ocasionando a informalidade do trabalho, a falta da assistência e seguridade social para as trabalhadoras deste setor. Este é um tipo de trabalho caracteristicamente feminino.

O bairro Progresso foi escolhido devido à alta incidência de facções de pequeno porte.

\section{Escolha das Participantes e Esclarecimento da Metodologia de Estudo}

Com a colaboração dos profissionais da unidade de saúde foi possível estabelecer contato com três mulheres com diagnóstico de lombalgia que durante conversa ao telefone mostraram-se disponíveis a participar da pesquisa, sendo então marcado um encontro individual com cada uma delas para prestar esclarecimentos quanto à metodologia da pesquisa deixando claro que as visitas seriam quinzenais. As participantes receberam uma espécie de calendário com datas e dias da semana onde iriam marcar como se sentiram naquele dia. Caso sentissem dor marcariam no calendário uma nota de o a 10 de acordo com a (EAV) Escala Análogo Visual (Agne, 2005).

Foi solicitado às participantes que marcassem que período do dia a dor começou, e o que elas fizeram para aliviar o sintoma.

A ideia de utilizar métodos como o calendário e a escala análogo visual era facilitar as anotações das participantes quanto aos sintomas e aos recursos de que dispunham para aliviá-los. Além de subsidiarem a interação com as famílias, constituíam-se em elemento concreto para encontros regulares, durante um período de tempo suficiente para criar uma rotina, condição ideal para a construção da relação de interlocução desejada. As anotações serviram mais como uma indumentária para garantir o estatuto de pesquisa do que como instrumento principal de captação de informações (Leite e Vasconcelos, 2006). 0 calendário foi elaborado a partir do modelo utilizado por Leite (citado por Leite e Vasconcelos, 2007) num estudo sobre a utilização de medicamentos e outros recursos terapêuticos para o enfrentamento das doenças infantis no âmbito familiar na cidade de Itajaí.

Nos dias dos encontros, foi utilizado um formulário de acompanhamento com o objetivo de esclarecer as marcações feitas pelas participantes. Os depoimentos realizados nestes encontros foram gravados. Estas informações ajudaram a compreender as informantes, o grupo a que pertencem e as lógicas de sua cultura (Travancas, 2005).

O estudo foi aprovado pelo Comitê de Ética em Pesquisa da Univali sob número 531/o7. Após o esclarecimento e a concordância das participantes em atuar no estudo, um termo de consentimento livre e esclarecido foi entregue para cada uma delas. A partir deste primeiro encontro, os demais foram agendados quinzenalmente. Além das visitas na residência das participantes, uma facção foi alvo de observação, e uma fase exploratória para a entrada em campo contemplou observações e tentativas de abertura de campos de pesquisa em indústrias têxteis e outras facções da cidade. 


\section{Discussão}

\section{O Que é a Dor nas Costas}

No início do trabalho de campo, as informantes mostravam-se impressionadas com alguém querendo estudar a dor nas costas, afinal:

Dor nas costas, quem não tem? Vocês dizem quando a gente vai no postinho que é normal, que tem que relevar! Relevar pra quem não está sentindo nada é uma coisa, agora, vamos trocar de lugar, vocês sentem minha dor e eu mando vocês relevarem, me ensinem então como que se faz pra relevar? (Rosa).

Isto declarou Rosa (uma mulher de 46 anos, mãe de três filhos, decidida e falante, mora no bairro há 26 anos e trabalha como costureira há 17 anos, sofre com dores nas costas há 1o anos), ao primeiro encontro, demonstrando um misto de sentimentos que permeavam entre o espanto e a revolta por alguém se preocupar com o assunto. Ficou evidente que nem sempre aqueles que dispõem do "conhecimento" para dar-lhe uma resposta e consequentemente o alívio ao seu sofrimento o fazem de maneira eficaz, pois, geralmente a atenção que se dá para a lombalgia é a indicação de um medicamento, repouso no leito, aplicação imediata de um suporte que proporcione imobilização (este quando necessário) e fisioterapia (Kendall, 1995).

Os profissionais de saúde em geral olham a lombalgia como uma causa física, (mecânica), uma alteração neuromuscular ou neurofisiológica, e que muitas vezes é vista como dor comum, que acomete grande parte da população e que, na maioria das vezes, é passageira. Mas quem sofre com a dor pode ver a lombalgia com os olhos de Lúcia (49 anos, divorciada e mãe de cinco filhos, mora no bairro desde de que nasceu, trabalha como costureira há 15 anos e sofreu com a violência doméstica praticada pelo marido alcoólatra por 11 anos) que diz: “A dor é horrível! Tem gente que diz que essa dor não é dor, mas é horrível!".

A partir destas e outras declarações percebeu-se que a proposta inicial de estudar o enfrentamento da dor lombar e identificar os recursos terapêuticos mobilizados foi ficando pequena, pormenorizada demais à medida que as informantes foram mos- trando o seu mundo, possibilitando enxergar a dor sob o seu ponto de vista.

É isto que se pretende apresentar aqui, para que as ações profissionais relativas à lombalgia possam ser mais atentas à realidade de quem a sente na prática, na expectativa de promover ações mais integrais aos cuidados de saúde da população.

Ao longo do trabalho de campo, as informantes (aqui serão chamadas pelos pseudônimos de Rosa, Lúcia e Jaqueline; Jaqueline é uma jovem senhora de 29 anos, divorciada e mãe de um menino, mora há pouco tempo no bairro, vindo da cidade vizinha Gaspar-SC, trabalha no ramo têxtil desde os 16 anos) foram dando destaque para alguns aspectos de suas vidas como: relação com o trabalho, família, profissionais de saúde, concepções a respeito da dor lombar, recursos terapêuticos mobilizados e adaptações em seu dia a dia. Num primeiro momento, para facilitar o processo de interpretação, os dados foram agrupados e denominados de categorias descritivas.

A análise dos dados levou à construção de dois segmentos analíticos: a dor lombar sob o aspecto da normalidade, vista pelo senso comum ou pelo público em geral, e a dor lombar íntima ou privada, vista por aquele que a sente.

\section{A Dor Lombar sob o Aspecto da Normalidade}

[...] Você quer fazer um estudo sobre dor lombar?! (Lúcia).

Esse questionamento e a expressão de Lúcia ao longo do processo de pesquisa repetiram-se em colegas de trabalho, de mestrado, familiares e amigos que demonstravam decepção quando era revelado que a temática do estudo era a dor lombar. Parecia não ser relevante!

De certa forma é até compreensível tal decepção, afinal, a dor lombar já deve ter sido sentida pela maioria dos decepcionados com maior ou menor intensidade e talvez por isso, pelo fato de a dor acometer um número expressivo de pessoas, ela seja interpretada como normal. Então por que estudá-la?

$\mathrm{Na}$ verdade, este aparente "descaso" por parte das informantes e das pessoas em relação ao tema demonstra que existe um motivo para que as pessoas interpretem a dor lombar como normal. 
Inicialmente é importante entender o que Helman (2006) preconiza sobre a dor e que pode aqui se reportar para a dor lombar. Para o autor, a dor é mais do que um simples processo neurofisiológico: há também fatores sociais, psicológicos e culturais que devem ser considerados, fazendo com que nem todo grupo social reaja à dor da mesma forma. A cultura em que a pessoa está inserida exerce grande influência na maneira como percebem e reagem à dor, em si mesmas ou em outras pessoas.

A dor é um fato privado, isto é, para sabermos se uma pessoa tem dor dependemos de uma demonstração verbal ou não verbal a respeito do fato. Quando isto acontece, a experiência e percepções privadas de dor tornam-se um acontecimento público e social; a dor privada torna-se um fenômeno público. Parte da decisão de tornar ou não pública a dor privada depende da interpretação individual do significado da dor. Se, por exemplo, a dor é considerada "normal ou anormal" (Helman, 20o6).

Partindo do aspecto cultural da dor foi possível iniciar o processo de entendimento sobre a dor lombar sob o ponto de vista das informantes, inseridas em uma cultura predominantemente germânica. Entender este aspecto torna-se relevante pelo fato de que durante as enchentes de 1983/1984 a cidade ficou em estado de calamidade pública e naquela conjuntura o governo municipal promoveu a reorganização da cidade, pela reatualização do mito da "capacidade de trabalho alemão". Forjava-se uma identidade germanizada pelo viés do trabalho para se reconstruir a cidade e para sanar um problema de maior alçada já percebido na época, que era a crise econômica da indústria na década de 1980. (Frostscher, 1998).

O governo municipal fez largo uso da germanidade para mostrar uma cidade habitada por um povo ordeiro e trabalhador. O elemento "trabalho alemão" passou não somente a servir como fator de distinção étnica, mas também como fator de diferenciação perante outras cidades e regiões do país. Neste período a mulher tornou-se uma importante força de trabalho por ser considerada, durante os discursos políticos da época, tão trabalhadeira quanto o homem (Frostscher, 1998).

Desta forma, torna-se possível entender o fato de as três informantes possuírem em comum, aspectos como a valorização de seu potencial de trabalho. Repetiam várias vezes que gostavam de trabalhar, que não faziam corpo mole por qualquer coisa. Não deixavam de trabalhar, nem de realizar suas atividades domésticas pelo fato de estarem sentindo dores nas costas, o que era preconizado em seu ambiente de trabalho e familiar.

[...] Se queixar pros outros por causa de dor nas costas dá a impressão de que você é mole (Lúcia).

[...] Eu aprendi desde cedo que a gente não tem que reclamar de qualquer dorzinha, tem que aguentar (Rosa).

[...] Tem gente que tem uma dorzinha e reclama (Jaqueline).

Estas declarações evidenciam que falar da sua dor e ainda falar da dor nas costas é sinônimo de fraqueza, então é melhor não falar e sim suportar. É o que foi dito por Rosa no início deste trabalho

\section{[...] Você tem que relevar!}

A grande questão é compreender por que as pessoas têm o comportamento de relevar a dor lombar. A partir deste pressuposto cabe refletir sobre o que Helman (2006) diz quanto aos aspectos sociais da dor. Segundo ele, a dor pública implica relação social, duradoura ou não, entre indivíduo com dor e outra pessoa ou pessoas. Outro aspecto importante a ser estabelecido é que a identidade feminina é produto social e reflexo do olhar do outro. Importa, antes de tudo, como e de que modo o outro a vê e não apenas a imagem que ela tem de si mesma (Vieira, 2005), o que, certamente, está relacionado às formas de cuidado de seu corpo e saúde.

A natureza dessas relações determinará, em primeiro lugar, se a dor será revelada, como isso será feito e a natureza das respostas. Para Helman, as expectativas do indivíduo com dor são importantes neste caso, principalmente em relação às reações possíveis à sua dor.

As pessoas com dor obterão o máximo de atenção e solidariedade se seu comportamento corresponde à visão social de como deve fazê-lo: se extravasando suas emoções, ou modificando sutilmente sua conduta. É a adequação de determinados sinais com os principais valores de uma sociedade que determina 
o grau de atenção recebido. Há, portanto, uma dinâmica entre indivíduo e sociedade através da qual o comportamento de dor e suas reações influenciam cada pessoa através dos tempos.

Para Alves e Rabelo (1999), a enfermidade dota-se subjetivamente de sentido à proporção que se afirma como real para os membros da sociedade que, por sua vez, a aceitam como real. Existe, justamente porque se origina no mundo do senso comum. Assim, a enfermidade é construção intersubjetiva, isto é, formada a partir de processos comunicativos de definição e interpretação.

As mulheres desta pesquisa sabiam a maneira como as pessoas reagem em relação à sua dor no âmbito familiar, de trabalho ou em relação aos profissionais de saúde. E por isso admitiam que ela fosse normal e que nada havia para ser feito a não ser relevar.

[...] Esses dias eu tava meio enjoada e falei pra minha cunhada que estava com dor nas costas, e ela disse que também tem dor nas costas, que tem isso, que tem aquilo, tem que levar, ela disse (Rosa).

$O$ fato de ter que relevar e conformar-se com a dor pode estar relacionado a um aspecto mencionado pelas informantes: as pessoas não acreditam que a dor nas costas realmente exista, e quando se referem à dor lombar estão falando de algo crônico, que as acompanha há anos. Tal dor não provoca sinais visíveis para que as pessoas possam caracterizar a existência de sofrimento como, por exemplo, o curativo de uma cirurgia, um membro engessado, a pedra retirada de um rim. É preciso algo que possa ser visto para caracterizar doença. Esta compreensão de que a doença precisa ser palpável, visível, vai ao encontro do que Boltanski (1989) exemplifica ao citar o caso de uma mulher que descreve com articulação e fundamento o episódio de pedra na vesícula de que foi acometida, explicando que elas foram retiradas e mostrando as pedras que ela guardava em um vidro.

[...] Mas os outros, se não aparece um corte fundo, alguma coisa, aí eles não acreditam, daí não está doente [...]. Uma vez eu disse pra minha mãe que eu tinha muita dor nas costas, aí ela nunca acreditava. Se eu tivesse doente mesmo, eu não tava aí forte, corada, indo trabalhar (Lúcia).

Estas declarações permitem duas interpretações. Uma é sobre o papel do doente e a doença, e a outra é a contribuição da ciência biomédica para este tipo de comportamento.

Para ilustrar o papel do doente refere-se aqui o recorte feito por Almeida e Coelho (2002) sobre o que Talcott Parson, principal teórico do funcionalismo norte-americano, desenvolveu sobre a "teoria do papel do doente". O doente teria um papel definido, que implica isenção das responsabilidades sociais, impossibilidade de cuidado a si mesmo, desejo de ficar bem e dever de procurar e cooperar com o tratamento médico.

No contexto em que se encontravam as mulheres participantes desta pesquisa, percebeu-se que não desempenhavam o papel de doente perante as pessoas que as rodeavam, pois continuavam trabalhando e desempenhando seus papéis sociais normais. Então não estavam isentas de suas responsabilidades sociais. A própria mãe de Lúcia diz isso quando afirma que se ela estivesse doente não estaria indo trabalhar. Elas eram capazes de cuidar de si e de seus familiares, e procuravam ajuda médica apenas em último caso, como refere Jaqueline:

\section{[...] Só vou no médico quando estou nas últimas.}

Canesqui (2003) define doença como um fenômeno social capaz de estabelecer uma relação entre as ordens biológicas e sociais, atingindo concomitantemente o indivíduo, seu corpo, a sociedade e as relações sociais. Muitas das indagações e significados, suscitados pela doença na sociedade, superam os estreitos limites biológicos do corpo e as explicações biomédicas.

Para a autora, a percepção da doença dá-se através de alguns sinais e sensações corporais, indicativos de que "algo" impede o funcionamento "normal" do corpo (dor, febre, não comer, não dormir, fraqueza), e pela incapacidade de realizar as atividades cotidianas de trabalhar, em qualquer modalidade assalariada ou não, assim vista por homens e mulheres.

Além deste significado, Minayo (1992) acrescenta o peso das contradições e conflitos sociais do sistema de dominação. Uma vez transposto e mediado pela relação estabelecida com as classes 
trabalhadoras, situa a doença na incapacidade para trabalhar produtivamente.

Este aspecto da produtividade é marcante nas falas das entrevistadas, uma vez que sua remuneração depende exclusivamente da produção, que não possuem benefícios trabalhistas. Para Vieira (2005), o trabalho como força estruturante da identidade feminina desempenha papel altamente significativo na atualidade, pois, se a mulher não trabalhar, nunca atingirá a forma mais expressiva de independência feminina, que só será alcançada pelo poder econômico, o qual é obtido principalmente pelo trabalho

A produtividade como marcador de saúde/doença é produto, parcialmente, das ciências biomédicas e coloca-se aqui não só à medicina, mas também à fisioterapia, que sofreu grande influência do pensamento biologicista. A fisioterapia surgiu devido à predominância de uma assistência curativa, recuperativa e reabilitadora, voltada para o processo de reabilitar para a volta ao trabalho, marcante no período da industrialização e que vigora até os dias atuais.

Para uma melhor compreensão da contribuição biomédica, para a conformação desta concepção profissional, é possível incluir nesta análise uma declaração de um médico ortopedista, chamado Gordon Wadell, encontrada no prefácio de um livro sobre distúrbios da coluna lombar, que dizia que não se deve transformar uma queixa subjetiva de saúde em uma condição clínica. Ele insinuava que o pensamento médico corrente considera a dor lombar como uma "doença”, e que isto não pode ser aceito.

No âmbito da sociedade blumenauense, é exemplar o artigo publicado em um jornal local de grande circulação e lido pela maioria da população ali residente intitulado "Lombalgia" (Zillig, 2008). 0 autor classifica a dor lombar como sendo comum. Afirma que, geralmente, as pessoas se classificam como sofredoras de dores na coluna, mas nenhum médico dá este diagnóstico ao seu paciente. Tais rótulos são autoassumidos. Finaliza o artigo dizendo que a vida civilizada, que a maioria das pessoas vive sem fazer grandes exercícios, faz com que se tenha uma estrutura músculo-esquelética digna de um frango de granja, ou seja, dor nas costas é normal.

Ambos os autores citados acima desclassificam a subjetividade da dor lombar, indo ao encontro do que diz Camargo Jr. (2003) sobre a teoria das doenças. Para ele (p. 79), "todo trabalho médico está voltado para a identificação e eliminação, quando possível, das doenças e das lesões que as causam. Tudo o mais é secundário, até mesmo o indivíduo que incidentalmente traz a doença. 0 saber médico é sobre a doença, não sobre o homem. Que só interessa ao profissional por ser o terreno onde a doença evolui".

A dor lombar não é exceção a esta lógica. Prescreve-se um analgésico e/ou a melhora da força muscular de "frango de granja", mas não se questiona a forma de organização do trabalho da cidade nem o status quo da múltipla jornada de trabalho feminina

Neste contexto, como não entender que a população considere a dor lombar normal, comum, irrelevante, se o senso comum e o próprio médico dizem que é assim que se deve proceder?

Dá alta porque isso é normal, isso aí todo mundo diz que sofre da coluna, se fosse só por isso não ia ter mais ninguém trabalhando! (Rosa).

Sei que eles não acreditam (Lúcia).

A partir destas reflexões é possível reportar-se ao pensamento de Tesser (2006) de que a profissão médica decide quais dores ou doenças são autênticas, imaginárias ou simuladas. Os termos com que os profissionais de saúde que praticam a docência explicam aos seus alunos a natureza da dor ganham em precisão objetiva, e os termos de referência subjetiva com os quais os pacientes se esforçam para discernir e dar significado para seus padecimentos esvaziam-se e perdem seu poder de comunicação. A sociedade reconhece este julgamento profissional e adere a ele. A dor objetiva pode vir a ser sofrimento apenas através do olhar de uma pessoa, mas atualmente é o olhar profissional que mais determina a relação do paciente com sua experiência.

Ah! Eu não vou no médico! Não adianta! Eu vou é trabalhar! $O$ dia que eu não aguento eu vou no médico, daí ele me dá uma injeção e fico em casa uns dois dias para sarar e pronto! Na fisioterapia elas só me diziam que eu tava ali por causa da coluna, mas coluna tem tanta gente né! Daqui um mês a senhora vai estar aqui de volta, issoé coisa que vai e vem (Lúcia). 
Outro aspecto relevante que as informantes deixaram transparecer são os recursos terapêuticos que utilizam para alívio da dor lombar. É visível que o recurso mais utilizado é o medicamento, afinal, vivese em uma cultura que valoriza a medicação. Sem ter outra saída, os pacientes aprendem a conceber sua própria dor ou adoecimento como fato clínico objetivo em um processo cíclico em que o indivíduo aprende a se ver como consumidor de anestesias, sintomáticos, quimioterápicos etc. Combater os sintomas dentro da medicina pode dar-se pelo dever ético de sedar a dor e aliviar o sofrimento, como regra geral, ou pode ser confundido com o comodismo profissional e com a impotência do saber biomédico ao se defrontar com queixas e sofrimentos não enquadráveis na grade nosológica (Tesser, 2006).

Como a maioria dos profissionais de saúde é formada por uma metodologia fragmentadora e curativa, em que o problema de saúde é visto como físico, localizado, fica sem poder dar sentido ou explicação satisfatória aos adoecimentos.

Muitas vezes, em seu dia a dia, a mulher esgota suas energias entre trabalho e casa e acaba deixando de cuidar de si mesma. Colocando sempre à frente o trabalho e a família, fazendo jus ao título de supermulher, aquela que não tem dor não precisa de ajuda, não reclama, e quando o faz, dizem seus familiares, médicos e patrões que é normal, que tem que relevar, que não pode ser mole!

[...] Meus filhos às vezes não entendem, é complicado dar conta de tudo, além de eu trabalhar todo dia ainda tenho tudo em casa pra dar conta (Lúcia).

Questões como a informalidade do trabalho, a importância dada à produção e a irrelevância perante o fato de a maioria das trabalhadoras apresentarem quadros de lombalgia, puderam ser encontrados também na visita realizada a uma das várias facções que existiam no bairro onde a pesquisa foi realizada.

Esta irrelevância diante da lombalgia pode ser melhor entendida ao analisar as novas formas de produção adotadas na década de 1990, quando as empresas de Blumenau sofreram a abertura do mercado às importações. As empresas reestruturaram o trabalho e eliminaram postos de trabalho. As facções que acabaram surgindo são marcadas por intensas jornadas de trabalho; a remuneração dos trabalhadores é proporcional à produção por peça costurada; eles trabalham sem registro e sem qualquer condição de segurança ocupacional, legal, emocional, ergonômica ocasionando a informalidade do serviço e consequentemente a falta de assistência e seguridade social (Petry, 200o).

Desenvolve-se, então, uma precarização, sem paralelos, da força humana que trabalha, que oscila entre a busca de trabalhos precários e a vivência do desemprego. Há perenidade e superfluidade do trabalho porque os capitais não podem se reproduzir sem a extração do sobretrabalho. Por outro lado, podem se reproduzir intensificando o trabalho daqueles que se encontram no mundo produtivo e expulsando um enorme contingente que não tem mais como ser incorporado e absorvido pelo mundo produtivo (Antunes, 2008).

É importante considerar que, segundo Brito (2000), na verdade, a precariedade sempre esteve associada ao trabalho feminino, uma vez que, mesmo quando a insegurança, a instabilidade e o desemprego atingem toda a população de trabalhadores, o trabalho masculino tende a estabilizar-se, enquanto que o feminino tende a manter-se incerto e irregular.

Para o caso de Blumenau, pode-se comparar com o relatado por Lerolle (1995, citado por Brito, 200o). O autor destaca a contradição entre os discursos que valorizam a autonomia e a ausência de meios para exercê-la efetivamente, citando o exemplo das operárias de uma confecção que foram organizadas, de forma autoritária e sob forte exigência de produção, em "grupos autônomos", e restabeleceram rapidamente a mesma divisão do trabalho anterior assumindo a legitimidade daquela forma de trabalho. Também na situação aqui estudada, as mulheres e a sociedade aceitam e legitimam esta forma precária de organização do seu trabalho - atendendo assim a uma necessidade desta sociedade de resolver o problema de um setor produtivo à custa da subjugação do trabalho feminino.

\section{A Dor Sentida}

Quem sente é a gente! (Rosa).

Durante o processo de pesquisa o aspecto da normalidade da lombalgia parecia ser prevalente, mas, 
à medida que a relação de vínculo entre a pesquisadora e as informantes ia tornando-se mais intensa, estas passavam a modificar o seu discurso, deixando transparecer que a lombalgia não era um fato sem importância em suas vidas como todos a classificam, mas como uma dor sentida por elas em seu dia a dia e denominada por Jaqueline como:

\section{[...] A minha dor nas costas, a dor que eu sinto!}

A lombalgia, quando suas portadoras têm capacidade de avaliá-la, é revelada como algo que incomoda, que irrita, chateia, provoca sofrimento, influencia o dia a dia.

A dor é horrível! (Jaqueline).

Incomoda bastante, irrita, deixa a gente bem irritada porque dói! (Rosa).

A dor sentida passou a ser relatada pelas informantes no momento em que perceberam que não haveria censura de qualquer tipo de familiares, patrões, colegas de trabalho ou profissionais de saúde. Acredita-se que elas perceberam que o foco da pesquisa não era julgá-las ou repreendê-las, mas tentar entendê-las como mulheres que trabalham no setor têxtil de uma cidade como Blumenau e que sentem a lombalgia. Assim, Rosa, Lúcia e Jaqueline tiveram cada uma em seu momento a oportunidade de desabafar sobre a dor que sentiam e suas consequências.

[...] Vocêjá deve ter sentido dor na vida, né?! Então imagine isso todo dia te incomodando, claro que tem dias que dói menos, mas mesmo assim, tem sempre alguma coisa ali te lembrando que existe sabe? (Lúcia).

[...] Tudo tem que ter o seu jeito. $\varepsilon$ pra limpar a casa, pra estender a roupa no varal, eu coloco um balde em cima da cadeira pra não ficar me abaixando. [...] Não posso pegar meu neto no colo, não posso varrer, não posso capinar em volta da casa. Ainda bem que tenho meu menino mais novo que me ajuda, mas não gosto de ficar pedindo pra ele. [...] Todo dia eu choro sozinha lá no quarto! Todo mundo cobra! Tá tudo tão difícil e eles ficam cobrando ainda da gente! [...] A dor da gente só a gente sabe o que passa, dizem que é coisa da idade, mas é porque os outros nunca passaram por isso (Lúcia).
As situações aqui referidas por Lúcia foram também encontradas por Castro e colaboradores (1994) ao estudar mulheres portadoras de LER (Lesões por Esforço Repetitivo). As situações vividas assemelham-se aos conflitos relativos à divisão do trabalho doméstico. A relação com os filhos é sensivelmente alterada. Com a mãe lesionada estes passam a colaborar nas tarefas domésticas, contudo, para a mãe a situação é muito desconfortável.

A dor provoca limitações que vão além do aspecto físico, também abrange aspectos psicológicos e sociais que interferem nas atividades do cotidiano, o que impede uma satisfação pessoal provocando situações de chateação e esgotamento.

[...] Quando você está com dor é melhor ficar calada pra não brigar com ninguém, a gente tem vontade de ficar quieta, não quer saber de papo, daí as pessoas acham que a gente não quer conversa com elas, mas não é! É a dor que incomoda! [...] Eu tenho fama de mal-humorada porque eu quase não falo, mas também, passe o dia inteiro e a noite com dor, sem dormir até, porque não tem posição que passe! [...] Não consigo brincar com meu filho, se me abaixar, como eu disse, não indireito! [...] Isso vai indo que te esgota! (Jaqueline).

A dor provoca a sensação de medo, insegurança para qualquer tarefa. A dor requer adaptações até para vestir a roupa e calçar o sapato, além de proporcionar alterações na forma de caminhar, adotando posturas que defendam seu corpo da dor.

[...] Sem eu perceber eu ando igual uma deficiente, manco, a perna repuxa, parece que finca uma agulha. [...] Tem coisas que eu não faço, mas vou te dizer por quê, tenho medo de fazer e depois a dor piorar! Sabe que a gente se priva das coisas, sempre pensando na dor, você pensa assim, será que se eu fizer isso vou ficar mais doída? E aíacaba não fazendo, porque a gente sabe que depois quem sofre é a gente! [...] (Rosa).

Para Silva e Arcanjo (2006), quando temos a sensação de medo passamos a não viver novas experiências estacionando e dificultando situações de vida, produzindo insegurança, tabus, irrealidades, superstições, conceitos errôneos e preconceitos, o que assimilamos de forma verbal ou em gestos. No 
caso da lombalgia, o medo referido por Rosa faz com que ela estabeleça resistência e obstáculos a certos afazeres, na crença de que a dor poderá surgir e ela não poderá controlá-la, além de ter que, mais uma vez, sentir em si o sofrimento que a dor proporciona. No entanto, a produção nas facções tem que continuar, é preciso reinventar a maneira de realizar suas atividades laborais tanto em casa como no trabalho para que o sofrimento da dor possa ser substituído pelo prazer do trabalho (Silva, 2008).

Depois de ouvir das participantes o que a dor sentida lhes proporciona, percebeu-se que este momento da pesquisa era único, revelador e reflexivo, porque os relatos realizados eram íntimos, talvez nunca antes ditos, ou, talvez, nunca compreendidos. Falar sobre o sofrimento passou a ser irrelevante, considerado fraqueza.

Nesta reflexão percebe-se que a dor é mais do que um sintoma que se pode eliminar na prática clínica. Não é possível considerar aquele que sente dor apenas pelo foco organicista, é preciso considerar as experiências trazidas pela dor que são particulares e intransferíveis.

\section{Reflexões Finais}

A lombalgia para as mulheres trabalhadoras da indústria têxtil de Blumenau apresenta-se como uma espécie de conflito entre algo normal, sem importância e a dor sentida, limitante, que traz sofrimentos e angústias.

Primeiramente, exige o desenvolvimento do papel de mulher, que auxilia ou mantém sozinha o sustento da casa. Ela desempenha uma atuação produtiva dentro de um sistema que passou por um processo de reestruturação e que atualmente apresenta um modelo marcado pela precarização do trabalho, mas que exige pessoas fortes, que não se deixem abater por qualquer coisa, como uma simples dor nas costas. Uma mulher feminina, que precisa desempenhar seu papel de mãe, esposa, filha, que cuida da casa, não se queixa, não é "mole".

Mulheres que atendem ao esperado papel social construído pela constituição dos padrões de família, que como reprodutoras e cuidadoras, esquecem de si mesmas e, mais recentemente, constituíram-se boas trabalhadoras/profissionais sem abrir mão das funções anteriores, objetivando sempre compatibilizá-las, como se só a elas coubesse a superação das dificuldades e contradições inerentes ao desempenho dessa multiplicidade de papéis, como bem descreve Badinter (1994, citada por Fonseca, 1999).

A mulher que os outros veem e não conseguem enxergar desempenhando o papel de doente. Afinal, nada nela aparece que confirme tal rótulo, nem mesmo os profissionais da saúde ou a comunidade legitimam o seu sofrimento, então, por que ela mesma ou os mais íntimos assim a classificariam?

O conflito parece intensificar-se quando esta dor que a princípio apresenta-se como normal, passa a influenciar fortemente a vida dessas mulheres. Proporciona alterações físicas, sociais e psíquicas. Quando isso acontece essa mulher produtiva tenta de alguma forma assumir o papel de doente, esforçando-se para demonstrar seu sofrimento, expondo suas queixas, limitações e angústias frente à dor. No entanto, o sistema formado por família, serviços de saúde, trabalho e sociedade não permitem que isso aconteça, fazendo com que elas se calem e admitam que é preciso relevar a dor nas costas.

A dualidade da lombalgia é marcante, pois mulheres que têm dor, real, sentida no dia a dia e com um impacto importante às suas vidas - esforçam-se por negligenciá-la.

O resultado do conceito de lombalgia construído é de algo inerente à vida. 0 que não permite que nem mesmo elas assumam a dor como doença, não tendo então o direito de sentir-se doente, e não cobrando esse direito na sociedade.

Diante desse cenário não foi possível encontrar um enfrentamento, ou seja, a lombalgia, por não ser considerada doença, não é enfrentada, e, portanto, não há procura por tratamento de forma sistemática. Sendo interpretada como algo inerente à vida, algo normal, não provoca um itinerário terapêutico propriamente, apenas formas esporádicas de alívio momentâneo e algumas adaptações nas atividades cotidianas.

Em uma sociedade de colonização germânica, que se utiliza de pretensos preceitos de uma cultura do "trabalho alemão" como o grande valor de sua gente e que se reorganizou para preservar o setor têxtil produtivo sacrificando as condições de trabalho, o discurso aceito e reforçado (nos serviços de saúde, 
nos meios de comunicação) é de que a lombalgia é normal, tem que relevar, servindo assim para manter um sistema produtivo (do principal setor da economia local) precarizado, muitas vezes não legalizado, mas aceito na cidade como forma legítima e comum de trabalho - as facções caseiras que prestam serviços de corte e costura para as indústrias têxteis de Blumenau.

É preciso dar condições dignas de trabalho para essas mulheres. Pode-se partir da regulamentação das facções geradoras de emprego assegurando os direitos trabalhistas. Para isto, necessita-se de uma ação fiscalizadora efetiva por parte dos órgãos competentes, alterações na carga tributária e diminuição da burocracia para a regulamentação. Fazemse necessárias ainda alterações ergonômicas no ambiente de trabalho. Mas, sem dúvida, ainda mais relevante é considerar o sofrimento destas mulheres como real, e, para isto, é preciso rever a atuação do profissional de saúde frente à lombalgia, visto que a sua maneira de atuar influencia na percepção das pessoas sobre o problema.

É importante para o profissional considerar aspectos da vida, da percepção pessoal, socioeconômica e cultural das pessoas no processo saúde/doença buscando uma atuação mais integral e menos objetiva. É preciso dar as mãos aos sujeitos que recorrem aos serviços de saúde, para que juntos (profissionais de saúde e comunidade) possam encontrar um caminho para a melhora. Faz-se necessário abandonar a atitude simplista e acomodada que resume a lombalgia como um problema biológico que acomete a maioria da população. É preciso considerar o entendimento de quem convive com a lombalgia, respeitando a sua posição e estimulando a busca conjunta por uma terapêutica eficaz, conciliando as interpretações a respeito do problema.

\section{Referências}

AGNE, J. E. Eletroterapia: teoria e prática. Santa Maria: Orium, 2005.

ALMEIDA, F.; COELHO, M. T. A. D. Conceitos de saúde em discursos contemporâneos de referência científica. História, Ciência, Saúde - Manguinhos, Rio de Janeiro, v. 9, n. 2, p. 315-333, 2002.
ALVES, P. C.; RABELO, M. C. M. Experiência de doença e narrativa: significação e metáforas na experiência da enfermidade. Rio de Janeiro: Fiocruz, 1999.

ANTUNES, R. As formas de padecimento no trabalho. Saúde e Sociedade, São Paulo, v. 17, n. 4, p. 7-10, 2008.

BOLTANSKI, L. As classes sociais e o corpo. 4. ed. São Paulo: Paz e Terra, 1989.

BRITO, J. C. Enfoque de gênero e relação saúde/ trabalho no contexto de restruturação produtiva e precarização do trabalho. Cadernos de Saúde Pública, Rio de Janeiro, v. 16, n. 1, p. 195-204, 2000. CAMARGO JR, K. R. Biomedicina: saber e ciência. São Paulo: Hucitec, 2003.

CANESQUI, A. M. Os estudos de antropologia da saúde/doença no Brasil na década de 1990. Ciência e Saúde Coletiva, Rio de Janeiro, v. 8, n. 1, p. 109-124, 2003.

CAROSO, C.; NÚBIA, R.; ALMEIDA FILHO, N. Nem tudo na vida tem explicação: explorações sobre causas de doenças e seus significados. In: LEIBING, A.; CAMARGO JR, K. R. (Colab.). Tecnologias do corpo: uma antropologia das medicinas no Brasil. Rio de Janeiro: Nau, 2004. p. 152-153.

CASTRO, A. L. et al. Mulher, muler: saúde, trabalho, cotidiano. In: ALVES, P. C.; MINAYO, M. C. S. Saúde e doença: um olhar antropológico. Rio de Janeiro: Fiocruz,1994. p. 141-152.

FERREIRA, J. O corpo sígnico. In: ALVES, P. C.; MINAYO, M. C. de S. (Org.). Saúde e doença: um olhar antropológico. Rio de Janeiro: Fiocruz, 1994. p. 101-111.

FONSECA, R. M. G. S. Mulher, direito e saúde: repensando o nexo coesivo. Saúde e Sociedade, São Paulo, v. 8, n. 2, p. 3-32, 1999.

FROSTSCHER, M. Etinicidade e trabalho alemão: outros usos e outros produtos do labor humano. 1998. Dissertação (Mestrado em História) - Universidade Federal de Santa Catarina, Florianópolis, 1998. 
HELMAN, C. G. Cultura, saúde e doença. Porto Alegre: Artes Médicas, 2006.

KENDALL, E. Músculos, provas e funções. São Paulo: Manole, 1995.

KNOPLICH, J. Enfermidades da coluna vertebral: uma visão clínica e fisioterapêutica. 3. ed. São Paulo: Kobe, 2003.

LEITE, S. N.; VASCONCELLOS, M. P. C. Negociando fronteiras entre culturas, doenças e tratamentos no cotidiano familiar. História, Ciência, Saúde Manguinhos, Rio de Janeiro, v. 13, n. 1, p. 113-128, 2006.

LEITE, S. N.; VASCONCELLOS, M. P. C. Construindo o campo de pesquisa: reflexões sobre a sociabilidade estabelecida entre pesquisador e seus informantes. Saúde e Sociedade, São Paulo, v. 16, n. 3, p. 169-177, 2007.

MINAYO, M. C. S. O desafio do conhecimento: pesquisa qualitativa em saúde. São Paulo: Hucitec; Rio de Janeiro: Abrasco, 1992.

PETRY, S. M. V. A fibra tece a história: a contribuição da indústria têxtil nos 150 anos de Blumenau. Blumenau: Sintex, 2000.

SIMMONDS, M. J. Fisiologia do exercício clínico, afecções músculoesqueléticas, neoplásicas, imunológicas e hematológicas. Rio de Janeiro: Guanabara Koogan, 2002.

SILVA, C. A. F. da. A gestão de si na reinvenção das normas: práticas e subjetividade no trabalho. Saúde e Sociedade, São Paulo, v.17, n.4, p.111-123, 2008.
SILVA, R. M.; ARCANJO, A. Saber popular sobre dores nas costas em mulheres nordestinas. Ciência e Saúde Coletiva, Rio de Janeiro, v. 12, n .2, p. 389-397, 2006.

SILVA, R. W. Trabalho e saúde na indústria têxtil de Blumenau - SC. 2007. Dissertação (Mestrado em Gestão de Políticas Públicas) - Universidade do Vale do Itajaí, Itajaí, 2007.

TESSER, C. D. Medicalização social (I): o excessivo sucesso do epistemicídio moderno na saúde. Interface, Comunicação, Saúde, Educação, Botucatu, v. 9, n. 18, p. 61-76, 2006.

TRAVANCAS, I. Fazendo etnografia no mundão da comunicação. In: BARROS, J. Métodos e técnicas de pesquisa em comunicação. São Paulo: Atlas, 2005. p. 98-109.

UCHOA, E.; VIDAL, J. Antropologia médica: elementos conceituais e metodológicos para uma abordagem da saúde e da doença. Cadernos de Saúde Pública, Rio de Janeiro, v. 10, n. 4, p. 497504, 1994.

VICTORA, G. C.; KNAUTH, D. R.; HASSEN, M. N. A. Pesquisa qualitativa em saúde: uma introdução ao tema. Porto Alegre: Tomo, 2000.

VIEIRA, J. A. A identidade da mulher na modernidade. Delta, São Paulo, v. 21, p. 207-238. Número especial. Disponível em: <www.scielo.br/scielo.php?pid=So102$44502005000300012 \&$ script $=$ sci $_{-}$ abstract\&tlng=pt $>$. Acesso em: 4 jan.2010.

ZILLIG, C. Lombalgia. Jornal de Santa Catarina, Blumenau, 3 mar. 2008. p. 32.

Recebido em: 15/05/2009

Reapresentado em: 15/01/2010

Aprovado em: 08/02/2010 